\title{
LER EM VOZ ALTA: PRÁTICAS DE ENSINO NO SECUNDÁRIO E A FORMAÇÃO CULTURAL DAS ELITES BRASILEIRAS NO SÉCULO XX
}

\author{
READING ALOUD: TEACHING PRACTICES IN HIGH SCHOOL AND THE \\ CULTURAL FORMATION OF BRAZILIAN ELITES IN THE $20^{\mathrm{TH}}$ CENTURY
}

\author{
Rejane Rodrigues Almeida de Medeiros |Lattes | rejane_almeidademedeiros@yahoo.com.br \\ Universidade Federal de São Carlos \\ Luzmara Curcino | Lattes | luzcf@hotmail.com \\ Universidade Federal de São Carlos
}

Resumo: Neste artigo, nosso objetivo é analisar representações do ensino da leitura nas aulas de português do curso secundário brasileiro, manifestas em livros escolares editados na primeira metade do século XX, de modo a depreender as práticas de leitura que eram priorizadas, tendo em vista a função sociocultural, distintiva e hierarquizadora da escola secundária nesse período, destinada prioritariamente às elites dirigentes do país. Subsidiados por princípios e reflexões da História Cultural da leitura e a partir de um corpus constituído com obras didáticas adotadas no secundário, a saber, Céu, terra e mar (1914), de Alberto de Oliveira, Manual de califasia e arte de dizer (1930), de Silveira Bueno, O idioma nacional na escola secundária (1935), de Antenor Nascentes, e Português através de textos (1969), de Magda Soares, constatamos que no curso secundário brasileiro fomentavam-se especialmente práticas de ensino da leitura em voz alta. Essa leitura oralizada dispunha de atenção especial nas recomendações dessas obras didáticas, estabelecendo uma aproximação muito estreita com a tradição da arte retórica, com o objetivo de desenvolver habilidades específicas relativas ao domínio da eloquência, que representava um dos atributos essenciais na formação dos filhos da elite nacional, de início agrária e progressivamente urbanizada, nesse período de formação e consolidação do Estado brasileiro.

Palavras-chave: História do ensino da leitura. Ensino secundário. Leitura em voz alta. Livros escolares. Eloquência. 
Abstract: Our objective in this article is to analyze the representations of the teaching of reading manifested in schoolbooks edited in the first half of the $20^{\text {th }}$ century and used in Portuguese language classes of Brazilian high school. This topic was chosen, in order to understand the reading practices that were prioritized, in view of the socio-cultural, distinctive and hierarchical function of the secondary school in that period, intended primarily for the leading elites of the country. Supported by principles and reflections of the Cultural History of Reading, and from a corpus formed by didactic works adopted in high school, namely, Céu, Terra e mar (1914), by Alberto de Oliveira, Manual de califasia e arte de dizer (1930), by Silveira Bueno, O idioma nacional na escola secundária (1935), by Antenor Nascentes, and Português através dos textos (1969), by Magda Soares, we found that in the Brazilian high school, reading out loud was especially encouraged, since it had special attention in the recommendations of these didactic works, establishing a very close approach with the tradition of the rhetorical art with the objective of developing specific skills related to the domain of eloquence, which represented one of the essential attributes in the formation of the children of the national elite that was moving form an agrarian to a progressively urbanized area in this period of Brazilian State formation and consolidation.

Keywords: History of teaching of reading. High school teaching. Reading aloud. Schoolbooks. Eloquence.

\section{Introdução}

Nas primeiras décadas do século XX, a leitura em voz alta foi uma prática muito valorizada na escola e, a leitura em silêncio, ao funcionar como uma etapa de preparação para a realização da boa leitura oral, não constituiu objeto de maior discussão em livros escolares ou revistas de ensino, nem tampouco integrou o rol de disposições normativas em documentos oficiais para o ensino da leitura nas classes do curso primário ou do secundário ${ }^{1}$.

\footnotetext{
${ }^{1}$ Embora não disponha de maior explicitude quanto a sua importância ou quanto aos objetivos e formas de seu ensino nos livros escolares ou em revistas e disposições normativas, nesse período, a incapacidade ou a dificuldade de ler em silêncio, apenas com o olhar, sem movimentar os lábios, era um indício de uma formação insuficiente, precária, deficitária, razão pela qual, sobretudo a partir do século XIX, aqueles que não dominavam essa técnica eram representados pejorativamente, como pouco alfabetizados ou como analfabetos. Cf. a esse respeito Chartier, 2009, p. 128-129. A ausência de indicações de como ensinar essa técnica, de recomendações de seu exercício, de qualificações de sua relevância pode ser compreendida como resultante do pressuposto de sua aquisição espontânea, simultânea e idêntica ao aprendizado da leitura oralizada, podendo ser tratada de forma mais eventual e acessória.
} 
A importância conferida à leitura em voz alta nas atividades na sala de aula não apenas perdura ao longo das séries iniciais até a escola secundária, como também se sofistica, tendo como objetivo o desenvolvimento de uma modalidade oralizada, que prime por um certo modelo de fluência e de expressividade, em conformidade com as peculiaridades requeridas na leitura de gêneros específicos, em dadas circunstâncias formais e ritualizadas e diante de auditórios determinados de antemão. Nesse contexto, o ensino da leitura oral estabelece uma aproximação muito estreita com a tradição da arte retórica, de modo a desenvolver habilidades específicas necessárias ao domínio da eloquência, qualidade que atuava como signo de distinção cultural da elite econômica e dirigente do país, a quem, até então, se destinava exclusiva ou prioritariamente o ensino secundário brasileiro à época.

Considerando os desafios de constituição e consolidação do próprio Estado brasileiro na primeira metade do século XX e as suas transformações em resposta às demandas de novos atores sociais da sociedade brasileira que se refletiram, entre outros, na expansão progressiva da oferta de vagas escolares, em leis garantindo direitos e obrigações relativos ao ensino, em formas e técnicas prioritárias de ensino em função dos públicos a serem formados e das divisões sociais que de antemão determinavam as finalidades de sua formação e sua destinação profissional, objetivamos, neste artigo, resultante de nossa pesquisa de doutorado ${ }^{2}$, levantar e analisar certas representações do ensino da leitura nas aulas de português do curso secundário brasileiro, inscritas em livros escolares editados na primeira metade do século XX e início da segunda, mais precisamente de 1914 a 1969. A partir dessas representações do ensino da leitura, procuramos depreender as práticas de leitura que eram então priorizadas no ensino, tendo em vista a função sociocultural distintiva e hierarquizadora que desempenhava a escola secundária nesse período, destinada às elites econômicas - de início agrárias - em um país que processualmente se urbanizava e se industrializava, o que exigia, de um lado, mão de obra com formação básica para responder a essa demanda e, de outro, mão de obra com formação superior para ocupar os cargos burocráticos do funcionamento do aparelho estatal e os postos dirigentes do Estado.

Para a análise proposta, valemo-nos de quatro importantes obras escolares editadas entre 1914 e 1969, a saber: Céu, terra e mar (1914), de Alberto de Oliveira, Manual de califasia e arte de dizer (1930), de Silveira Bueno, O idioma nacional na escola secundária

\footnotetext{
${ }^{2}$ Nossa tese de doutorado, intitulada Representações do ensino da leitura: as aulas de português na escola secundária brasileira (séculos XIX e XX), foi realizada junto ao Programa de Pós-Graduação em Linguística da Universidade Federal de São Carlos, sob a orientação da Profa. Dra. Luzmara Curcino Ferreira e com apoio financeiro da CAPES.
} 
(1935), de Antenor Nascentes, e Português através de textos (1969), de Magda Soares. Nossa análise dessas obras se norteou por princípios, reflexões e constatações da História cultural da leitura, em especial no que diz respeito a sua concepção discursiva da "representação" e de sua relação com a "prática", tais como definidas pelo historiador e especialista em história da cultura escrita no Ocidente, Roger Chartier (2002).

Segundo essa abordagem, na análise de toda e qualquer fonte, de todo objeto cultural, tal como as obras que constituem nosso corpus, é preciso compreender que não se está diante de um reflexo das práticas efetivas ali indiciadas. Elas podem ser antes o indício de sua raridade, de seu declínio, fruto de uma visada nostálgica do que teriam sido as práticas de outrora ou de uma projeção futura do que se visa fomentar. Assim, em nossa análise concebemos o que é enunciado, sob a forma de recomendação didática nesses livros, como representações das práticas de ensino da leitura e das práticas de leitura ali privilegiadas que, em consonância com o contexto social, histórico e cultural respondem às demandas, crenças e valores em especial dos grupos dominantes. As representações da leitura, e de seu ensino, expressas nas recomendações didáticas dessas obras sinalizam, assim, não apenas o modo como se objetivava o aprendizado da leitura, mas também as divisões sociais dos sujeitos que a distribuição desigual das competências de prestígio numa dada sociedade outorga a uma minoria em detrimento dos demais.

É preciso reconhecer no que foi enunciado nesses materiais seu estatuto de "representação" tanto da "prática" de ensino quanto da "prática" de leitura, seu funcionamento discursivo conforme as injunções próprias do campo pedagógico e seu impacto, tanto aquele idealizado quanto o efetivamente produzido sobre as práticas. Em nossa análise buscamos depreender das fontes analisadas as representações consensuais em vigor à época sobre a leitura, procurando observar que práticas eram prioritariamente recomendadas e validadas e também interpretar algumas das razões que as fundamentavam junto à escola secundária brasileira, instituição fundamental no processo de consolidação do Estado.

Tendo observado a preeminência que a leitura em voz alta adquire nesse nível de ensino à época, decidimos remontar à história dessa prática, por meio de um breve panorama; seguido de um levantamento e análise das formas de apresentação da oralização, em relação com o gesto e com o jogo fisionômico, tal como recomendada em livros escolares de português; para finalmente empreendermos a reflexão sobre as relações entre o ensino da leitura em voz alta, no curso secundário e a arte retórica, em consonância com as demandas de formação do público para o qual se destinou, inicialmente, o acesso ao nível secundário no país. 


\title{
1. Leitura em voz alta: breve panorama histórico
}

Alguns dos enunciados mais antigos sobre a leitura em voz alta no mundo ocidental, segundo Robins (1983), podem ser encontrados na primeira gramática grega, a Arte da gramática, de Dionísio Trácio, que foi elaborada entre os séculos II e I a.C. Conforme o autor, quando esse tratado foi escrito, a gramática era concebida como um dos artefatos de um esquema mais amplo de estudos propedêuticos para a leitura e compreensão da literatura grega clássica. $\mathrm{O}$ tratado se dividia em seis partes e a leitura exata (em voz alta), com a devida atenção ao gesto, à prosódia e à clara separação das palavras, era considerada sua parte mais nobre, por pertencer à atividade de crítica das composições literárias e de sua interpretação, no sentido de sua realização performática e modo a dar a devida existência a cada gênero, conforme previa Dionísio Trácio:

\begin{abstract}
Há de se ler atendendo ao gesto, à prosódia e à distinção das palavras. Pelo gesto vemos a qualidade da leitura, pela prosódia a arte, pela separação das palavras o sentido nelas contido, para que recitemos a tragédia de modo heroico, a comédia como a vida, as elegias estridentemente, a épica com vigor, a lírica melodiosamente e os lamentos com abatimento e como se se fosse chorar. Porque o que não se faz atento a isso anula as qualidades dos poetas e torna ridículos os hábitos dos leitores (DIONÍSIO TRÁCIO, 2002 , p. 36-37) $)^{3}$.
\end{abstract}

$\mathrm{Na}$ Antiguidade, a leitura em voz alta predominou sobre a leitura silenciosa. Nesse tipo de leitura, o ouvinte era levado a acreditar na existência de uma relação fidedigna entre o que estava escrito no texto e o que era oralizado. Para que isso ocorresse, era necessário um engajamento físico e emocional do leitor, que ao ler cederia ao texto seu aparelho vocal e seu corpo, unindo-se a ele pelo tempo de uma leitura, já que sua voz era o instrumento que possibilitava à escrita realizar-se em sua plenitude (SVENBRO, 2002, p. 48-49).

Esse modo de ler em voz alta, assemelhava-se aos ideais de performance preconizados ao orador. Assim, ele estabelece uma estreita relação com a arte retórica, que se tornou na época helenística, segundo Manacorda (2010, p. 78), "o conteúdo e o fim da instrução grega”. O ensino de retórica, que se realizava depois de concluídos os estudos de gramática, compreendia cinco partes: a invenção, a disposição, a elocução, a mnemo-

\footnotetext{
${ }^{3}$ No original em espanhol: Se há de leer atendiendo al gesto, a la prosodia y a la distinción de las palabras. Por el gesto vemos la cualidad de lo leído, por la prosodia el arte, por la separación de las palabras el sentido encerrado. Para que recitemos la tragedia de modo heroico, la comedia como la vida, las elegías estridentemente, la épica com vigor, la lírica melodiosamente y los lamentos com abatimiento y como si se llorase. Porque lo que no se haga em observancia de esto anula las cualidades de los poetas y hace ridículos los hábitos de los lectores.
} 
técnica e a ação. É com esta última parte, a ação, definida como a "arte de exibir-se, de disciplinar a postura e a voz, e, sobretudo, a arte de reforçar a palavra pelo valor expressivo do gesto” (MARROU, 1966, p. 314), que podemos perceber uma aproximação entre a leitura em voz alta praticada entre os gregos e o domínio da arte retórica requerido tanto nas disputas públicas da vida política, quando a ação oratória se reveste da maior importância que o próprio assunto, como também nas representações teatrais (Cf. ARISTÓTELES, 1986).

Na Roma Antiga, a leitura pública em voz alta, ou recitatio, foi largamente praticada e se prestava, muitas vezes, ao "lançamento" de obras literárias por seus autores. Era geralmente acompanhada por gestos corporais, de modo que voz e gesto conferiam à leitura um caráter de representação teatral (Cf. CAVALLO, 2002). Essa performance, de acordo com Manguel (1999, p. 282-283) "dava ao texto um tom que (supostamente) era aquele que o autor tinha em mente no momento da criação e, portanto, concedia ao ouvinte a sensação de estar perto das intenções do autor”. Nas escolas romanas, durante o período em que o aluno era confiado ao gramático, dos doze aos dezesseis anos de idade, preparando-se para os cursos superiores de retórica, exercitava-se a leitura oral, após a aprendizagem da escrita. No Livro I da Instituição oratória, de Quintiliano, uma obra "cujo intento é traçar o caminho do futuro orador a partir da mais tenra idade e formá-lo (instituere) de modo integral” (BASSETTO, 2015, p. 9), o autor romano indica os exercícios de leitura em voz alta que deveriam ser realizados nas escolas dos gramáticos:

VIII. 1. Fica faltando a leitura: por ela que o menino saiba onde deve tomar fôlego, em que lugar cortar o verso, onde começa e se conclui o sentido, quando é preciso elevar ou abaixar a voz, também o que deve ser dito conforme o movimento, mais lento ou mais rápido, com mais veemência ou com mais suavidade: isso não pode ser demonstrado a não ser no próprio trabalho (QUINTILIANO, I, t. I, 2015, p. 161).

Assim como em Aristóteles, em Quintiliano (XI, t. IV, 2015, p. 265-267), a actio, em especial a pronuntiatio e a gesticulatio são elementos determinantes na força persuasiva do orador e daquele que lê em voz alta. Por meio delas, as emoções podem ser suscitadas ou arrefecidas. A aproximação entre leitura oral e arte oratória, observada entre os gregos, permanece vigente entre os romanos. A leitura em voz alta, constantemente exercitada nas escolas dos gramáticos, culminava com o proferimento de discursos nas escolas dos retores. De acordo com Marrou (1966, p. 260), nessa espécie de ensino secundário preparatório aos cursos superiores de retórica, o estudo dos autores tinha início com a leitura 
expressiva, considerada extremamente difícil devido à ausência de separação das palavras e de pontuação na escrita e terminava com a recitação do texto aprendido de cor.

Embora se rarefizessem, a partir do século VI, as circunstâncias de leitura em voz alta em latim, leituras públicas em voz alta continuaram a ser realizadas em língua vulgar, nos mosteiros, nas cortes, nos campos e em festas populares e religiosas, durante a Idade Média. Nos mosteiros, na lectio monástica, lia-se em voz alta, ou sotto voce, "para desenvolver uma memória oral e vigorosa das palavras, base para a meditatio" (PARKES, 2002, p. 105). No mundo laico, reunir-se para ouvir alguém ler era uma prática comum e necessária, uma vez que era pequeno o número de pessoas alfabetizadas e o acesso a obras bastante limitado. Nas cortes ou nos campos, os textos eram lidos em voz alta para familiares e amigos, tanto com finalidade de compartilhar notícias, se instruir, apreciar textos e se entreter ou fortalecer valores e vínculos devocionais ou de pertencimento a uma comunidade. Além disso, podia-se ouvir um texto recitado, cantado ou encenado por jograis e trovadores em feiras e mercados (MANGUEL, 1999, p. 138-139).

No século XII, o gesto assume um lugar importante no pensamento da época. Hugue de Saint-Victor, em seu tratado sobre a formação dos noviços, citado por Zumthor (1993, p. 242), afirma que "um gesto é ao mesmo tempo movimento e figuração da totalidade do corpo”. Ao longo do Renascimento e da Idade Moderna, com a ampliação do acesso ao impresso, com a inserção progressiva dos brancos entre as palavras e partes do texto e de sinais ortográficos e editoriais diversos, acentuou-se o pronto reconhecimento visual das unidades que hoje nos são familiares (palavras, frases, períodos, parágrafos etc.), estimulando assim uma prática de leitura mais veloz, mais extensiva, para o que foi fundamental a ampliação do domínio técnico e a naturalização da leitura com os olhos, em silêncio.

Segundo De Certeau (2004), essa mudança significou o habeas corpus do leitor, ou seja, o direito de ler em liberdade, individualmente, sem que o que se estivesse lendo pudesse ser ouvido e se tornasse assim inevitavelmente público. Isso não inviabilizou que o trabalho de formação leitora e que as práticas de leitura em âmbito escolar continuassem a privilegiar a leitura oralizada, em voz alta. Não se tratava mais, neste período, das mesmas formas e finalidades que aquelas da Antiguidade e da Idade Média. O caráter ritualizado da leitura pública, fosse na igreja, fosse no teatro, fosse na política, exigia uma leitura articulada, em um ritmo reconhecível pelos contemporâneos desse período. Lia-se num ritmo distinto, imposto entre outras razões pelo tempo da articulação e verbalização da escrita. A fluência, segundo essa lógica, não correspondia a ler no ritmo como falamos, 
como se preconiza hoje em dia. Não apenas devemos aprender a ler no ritmo e com a 'naturalidade' com que falamos, como também devemos e podemos ler mais rápido que isso, por golpes de vista, em silêncio. Foi em prejuízo de uma ritualidade da leitura - de uma leitura ruminação de um mesmo texto lido e relido até ser apreendido de cor, em especial porque grande parte dos textos provinham do campo religioso e sua apropriação não podia esquecer sua sacralidade - e em benefício de um consumo maior e mais rápido de textos que se estabeleceu um progressivo predomínio da leitura silenciosa sobre a oralizada a partir do Renascimento e do desenvolvimento da imprensa. Esse processo é responsável, ainda hoje, pela representação negativa que é feita daqueles que, dado o seu baixo grau de letramento e da pouca familiaridade com a decodificação de textos, leem vocalizando.

Apesar da processual inversão do predomínio e do prestígio, da prática de leitura oralizada para a prática de leitura silenciosa, ao longo dos séculos XVI ao XVIII, isso não significou o fim do ensino e da valorização da leitura em voz alta. No século XIX, a tradição prestigiosa do domínio da arte da oratória - cuja formação permitia produzir textos que deveriam ser lidos em voz alta e cuja qualidade era mensurada pela fluência de decodificação de sua escrita e o impacto que poderia produzir justamente pela boa oralização em sua leitura - ocupava grande espaço em vários manuais de elocução destinados a atores ou oradores. Se o ritmo de vida moderno implicou ler de forma dessacralizada, mais rapidamente e em maior quantidade, isso não significou que, embora fosse essa a tendência geral e progressiva, a leitura oralizada não perdurasse em certos domínios, ainda gozando da autoridade que lhe consagrara a tradição. Em pleno século XX, no universo escolar das seletas de textos de prestígio e da leitura com finalidade pedagógica, a leitura em voz alta perdura e predomina, conforme as recomendações presentes nos livros escolares de português, editados no Brasil entre 1914 e 1966, que sugeriam uma leitura oralizada que, pela pronúncia e articulação adequadas das palavras, pausas e inflexões da voz, acompanhada de gestos e de um jogo fisionômico peculiar, transmitiria o sentido que se julgava ser aquele que o autor desejou dar ao seu texto.

\section{Oralização, gesto e jogo fisionômico: a leitura em voz alta recomendada em livros escolares de português}

Em 1914, a Livraria Francisco Alves - que havia sido criada em 1897, tornando-se a principal editora no segmento de livros didáticos no Brasil (Cf. HALLEWELL, 2005, p. 280) - publicou a antologia escolar Céu, terra e mar. Organizada pelo professor e poeta 
parnasiano Antonio Mariano Alberto de Oliveira, o livro era composto por textos em verso e em prosa e, segundo Pfromm Netto et al. (1974, p. 203) apresentava a "curiosidade de agrupar os trechos selecionados por ordem de assunto (manhãs, meios-dias, tardes, noites, estrelas, montanhas, o mar, árvores, flores, rios, florestas, etc.)”. Logo após o "preâmbulo", a primeira edição da antologia oferece "alguns conselhos sobre a leitura de versos" contendo uma lista de sete recomendações. Esses "conselhos" funcionam como um protocolo de leitura dos poemas reunidos no volume, ao indicar a leitura em voz alta como o modo de ler apropriado para essa forma literária. De acordo com esses mesmos "conselhos", depois de ler o texto previamente para si, realizando um trabalho preliminar, em que se examinaria o sentido e a pontuação do texto, o aluno deveria então ler oralmente, pronunciando claramente as sílabas e as palavras, respirando adequadamente para marcar pontuação e modulando sua voz, de modo a promover a entonação requerida pela emoção ou sentimento do texto:

Alguns conselhos sobre a leitura dos versos

I. - Para bem ler em voz alta, leia o aluno previamente e para si os versos que houver de dizer, examine-lhes o sentido [sic], compenetrando-se dele, e atenda à sua pontuação, a fim de respirar a tempo e acertadamente. É indispensável este trabalho preliminar.

II. - Para a pronunciação ser clara e precisa é mister articular bem todas as sílabas, saber sustentar as demoras nos acentos, e suspender a voz nas consoantes finais de sílaba ou de palavra.

III. - A entonação deve ser regulada pela emoção ou sentimento do texto. IV. - Desterre-se de vez das aulas a enfadonha cantilena com que é costume ler e recitar versos.

A monotonia desta espécie de cantochão escolar evita-se, evitandose, como aconselha um autor, a perseverança na mesma modulação, a semelhança nos finais dos versos e a repetição frequente das mesmas inflexões.

V. - A leitura, embora correta nas pausas e animada de certo calor, será imperfeita quanto à expressão, se o aluno não der o devido relevo ou realce às palavras e frases de valor.

Palavras e frases de valor são as que nos versos sobreexcedem [sic] às demais por sua importância expressiva, e como tais requerem sobre si recaia a nota musical da inflexão. [...]

O verso tem um ritmo essencial que deve ser respeitado, e é desagradável ouvi-lo soar como se fora prosa [...] (OLIVEIRA, 1914, p. 9-10, grifos do autor).

Orientações para o ensino da leitura em voz alta nas aulas de português do curso secundário aparecem também em $O$ idioma nacional na escola secundária, um manual do professor de português, que contém explicações sobre métodos e conteúdos de ensino, 
elaborado por Antenor Nascentes, então professor catedrático de português no Colégio Pedro II e publicado em 1935. Quando o livro de Nascentes foi editado pela Companhia Melhoramentos, já circulavam, desde o final dos anos de 1920, em revistas de ensino, como a Revista de Educação, artigos de pedagogistas ligados à Escola Nova, que criticavam a importância dada à leitura oral nas atividades de sala de aula ou mais precisamente aos usos, finalidades e formas de condução dessa atividade comumente realizada. Nesses artigos, se propagavam as vantagens da leitura silenciosa, com a finalidade de que esta última fosse mais praticada nas escolas primárias (Cf. VIDAL, 2011). Embora O idioma nacional na escola secundária integre a Biblioteca de Educação, um projeto editorial da Companhia Melhoramentos dirigido por Lourenço Filho, que tinha o objetivo de divulgar os princípios escolanovistas, as recomendações desse manual, no que concerne ao ensino da leitura em voz alta e silenciosa, divergem daquilo que preconizavam os educadores da Escola Nova ou ao menos não fazem as devidas recomendações segundo os princípios escolanovistas em circulação. Ao enfatizar a leitura oralizada como uma prática de leitura que deveria ocupar maior tempo de estudo na aula de português, em relação à leitura silenciosa, Antenor Nascentes recupera enunciados sobre esse modo de ler - os quais aparecem também na antologia escolar Céu, terra e mar, de Alberto de Oliveira -, que remetem a uma prática de leitura de longa data, influenciada pela arte retórica, que, por sua vez, sobreviveu na cultura escolar até pelo menos os anos de 1970.

Em seu texto, Antenor Nascentes, mesmo considerando a leitura silenciosa como um "grande instrumento de aquisição de conhecimentos" (Cf. NASCENTES, 1935, p. 66), sugere ao professor de português que o ler silenciosamente seja uma prática reservada ao ambiente doméstico ou à viagem de bonde:

Para leitura silenciosa, fora da classe, indicar-se-ão obras e trechos notáveis. [...] Além desta leitura em aula [leitura em voz alta de um trecho escolhido de uma antologia], cumpre sempre recomendar a leitura silenciosa de casa, de bonde (NASCENTES, 1935, p. 69-73).

Segundo o autor, ao contrário da leitura silenciosa, a leitura em voz alta deveria ser intensamente exercitada desde o primeiro ano do ensino secundário e, no terceiro ano, “podia-se declamar um episódio inteiro de Os Lusíadas" (NASCENTES, 1935, p. 44-46). Ao caracterizar a leitura oral, Nascentes divide a realização desta prática em duas partes, uma mecânica e outra intelectual, com base em um autor francês:

Legouvé divide a arte da leitura em duas partes: uma, que é material, o mecanismo, e compreende a emissão da voz, a respiração, a pronúncia, a 
articulação e a pontuação, e outra, a intelectual. Sem o domínio da primeira não se deve tentar a segunda; por isso deve ela preceder. (NASCENTES, 1935, p. 52)

O livro L’Art de la lecture à l'usage de l'enseignement secondaire, de Ernest Legouvé, sobre o qual se apoia Antenor Nascentes, tinha sido elaborado, em 1877, por encomenda do Ministério da Instrução Pública Francesa, para atender aos cursos de leitura instituídos à época nas escolas normais, colégios e liceus da França, sob a justificativa do grande valor cívico da leitura oral, requerida em atos públicos (CHARTIER e HÉBRARD, 1989, p. 188). Na referência que faz a Légouvé, Antenor Nascentes repete e conserva enunciados sobre a leitura em voz alta, de modo a promover uma continuação nas práticas de ensino da leitura descritas em um livro do século XIX. Assinala, desse modo, o autor brasileiro a sua adesão à permanência de uma tradição, afastando-se das discussões realizadas no âmbito da Escola Nova, que questionavam, como dissemos, desde a década de 1920, a preeminência de um tipo de leitura oral nas práticas de ensino da leitura, consideradas atividades de decodificação mecânica, com entonação artificial e finalidade (didática) em si mesma, em especial quando se trata da leitura oralizada coletiva realizada em sala de aula. Ao se valer da autoridade de um autor reconhecido na França, Antenor Nascentes apresenta ao seu leitor, o professor de português, a leitura oralizada como ainda sendo a maneira mais adequada de se ler na escola e de se aperfeiçoar formas específicas de leitura que dispõem de prestígio social, tais como a leitura expressiva e a recitação do verso.

A leitura expressiva é apontada por Nascentes como aquela que requer do leitor "assenhorear-se das ideias e dos sentimentos do autor para dar-lhes a devida expressão". Já a recitação do verso é descrita como “o ponto culminante da arte de dizer", visto que sua realização exige o domínio prévio das técnicas envolvidas na leitura expressiva (Cf. NASCENTES, 1935, p. 53). Para indicar os exercícios que devem ser realizados, tanto de leitura expressiva quanto de recitação do verso, Antenor Nascentes recorre ainda ao Manual de califasia e arte de dizer (1930), de Silveira Bueno - o qual, à época, lecionava Português e Califasia na Escola Normal de São Paulo -, citando literalmente este último. Assim, os exercícios de leitura expressiva deveriam ocorrer em três etapas: primeiramente, o aluno deveria fazer a leitura em voz baixa; em seguida, a leitura em voz média - essas duas formas de ler comporiam a modalidade simples, uma forma de preparação do leitor -; para finalmente realizar a leitura expressiva:

Começamos pela preparação do trecho que vamos ler. Para isto, lê-lo-emos primeiro em voz baixa: é uma espécie de pesquisa no terreno a fim de 
conhecer os obstáculos que iremos encontrar. Notar então os vocábulos difíceis, quer quanto à pronúncia, quer quanto à intelecção. Não deixar nenhum sem compreender, sem saber como deve ser pronunciado. Examinar depois a pontuação, as pausas, para regularizar a respiração. Medir a extensão dos períodos a fim de apanhar-lhes o ritmo [sic], o andamento, para que não nos aconteça vir a perder o fôlego no meio de um deles. Assenhorear-se dos pensamentos e dos sentimentos de maneira que possam ser bem interpretados. Examinar o equilíbrio geral do escrito, os diálogos, as interrogações, as exclamações, etc.

Percorrido assim o caminho, iniciamos a leitura em voz média. O primeiro perigo aparece imediatamente: a pressa. Queremos mostrar pela velocidade que sabemos ler. Dominar os nervos e colocar toda a atenção na articulação das palavras. Pronunciá-las vagarosamente, demorando-nos nos vocábulos de maiores dificuldades. Neste exercício não nos devemos preocupar, nem com o sentido da leitura, nem com as flexões da voz, nem com a pontuação. $\mathrm{O}$ que queremos é conseguir o domínio destas duas coisas preciosas: pronunciar bem, articulando corretamente, e respirar. [...]

[Na leitura expressiva] A inteligência, pois, vai trabalhar e a sensibilidade atuará também. A voz deverá flexionar-se repetida e frequentemente, sendo necessário maior perfeição respiratória. Na respiração estará por assim dizer todo o trabalho expressivo. Se nos faltar o fôlego preciso, a voz não será perfeita, os sons sairão defeituosos, as inflexões viciadas, perturbando a própria intenção das ideias.

O primeiro cuidado há de ser, por conseguinte, a respiração como guia das inflexões (SILVEIRA BUENO apud NASCENTES, 1935, p. 52-53, grifos nossos).

O domínio do mecanismo da leitura oral compreende a emissão da voz, a respiração, a pronúncia, a articulação e a pontuação. O mesmo é recomendado no texto que fornece "alguns conselhos sobre a leitura dos versos", com o qual Alberto de Oliveira abre a sua antologia escolar Céu, terra e mar, de 1914. Para Alberto de Oliveira, assim como para Antenor Nascentes e Silveira Bueno, os exercícios de leitura em voz alta têm início com uma leitura prévia, que o aluno deve fazer para si mesmo, a fim de conhecer o sentido do texto e sua pontuação.

Os enunciados sobre o modo correto de ler, manifestos nos textos didáticos desses três autores, pela relação parafrástica que estabelecem entre si, parecem formar uma rede discursiva que busca fomentar uma prática de ensino da leitura em que a leitura em voz alta, ou expressiva, ocupa lugar central e a leitura silenciosa e em voz baixa e média representa uma etapa preparatória para o bom desempenho da primeira ${ }^{4}$.

\footnotetext{
${ }^{4}$ A regularidade do que é enunciado nessas três obras indicia a necessidade de recomendação dessa prática de ensino, seja porque ela não fosse efetivamente empreendida nas aulas, seja porque talvez não fosse suficientemente realizada conforme a cultura escolar brasileira das primeiras décadas do século XX.
} 
Além do mecanismo de oralização do texto, descrito acima, de acordo com Antenor Nascentes, a leitura expressiva envolveria também o "jogo fisionômico", ou seja, a expressão facial provocada sobretudo pelos olhos e pelos lábios, que acompanha a leitura e que auxilia o auditório a sentir e a compreender o que ouve:

O jogo fisionômico depende do movimento dos músculos da face. A atuação dos nervos faciais sobre eles faz espelhar-se no rosto o nosso sentimento.

A expressão é dada sobretudo pelos olhos e pelos lábios; já houve quem dissesse que os olhos eram o espelho da alma (NASCENTES, 1935, p. $54)$.

Segundo Silveira Bueno, citado por Antenor Nascentes, após o aluno ter dominado as técnicas da leitura expressiva, este estaria apto a adentrar no campo da poesia, praticando a recitação do verso. Afirma o autor que

[...] só depois que se possui o pleno domínio da voz, da respiração, articulando perfeitamente, com o hábito da análise dos trechos, conhecendo as sutilezas do colorido, do movimento, das cadências e sabendo colocar nas palavras de valor a inflexão justa, é que se pode entrar no campo da poesia (SILVEIRA BUENO apud NASCENTES, 1935, p. 53-54).

Se para esses dois professores de português e autores de manuais didáticos, a leitura expressiva requer o jogo fisionômico, para eles, a recitação demanda também o gesto: A leitura simples exige do leitor apenas a voz; a expressiva já requer algum
jogo fisionômico; a recitação é inseparável do gesto (NASCENTES,
1935, p. 54). [...] O corpo deve estar em posição ereta, natural. Pés
ligeiramente afastados, o esquerdo avançado sobre o direito para facilitar a
gesticulação da mão direita, a mais movimentada. Evitem-se as oscilações,
que são desagradáveis à vista. Às vezes, poder-se-á dar um passo à frente,
atrás, para os lados. A cabeça deve estar direita, em posição natural,
acompanhando os gestos, sempre que for necessário. O movimento dos
braços deve ser sóbrio, podendo ser violento nos lances fortes. Nas mãos,
a grande dificuldade dos atores, é que está toda a alma da gesticulação.
Ficam elas geralmente abertas, com os dedos ligeiramente separados,
desempenhando grande papel o index. Corrigem-se os cacoetes de
balançar as mãos, segurar no paletó, pôr as mãos para trás e outros
(NASCENTES, 1935, p. 54).

Continua o autor do Manual de califasia e arte de dizer afirmando que cada poe- 
sia deve ser interpretada de forma singular, conforme o gênero poético a que pertença. Assim, "uma ode não pode ter a mesma interpretação de uma fábula" e "uma composição leve, graciosa [...] não pode ser dita de maneira igual a uma outra profunda e comovedora” (SILVEIRA BUENO, 1930, p. 158-159). Essa ideia de que, durante a leitura em voz alta, o leitor deve expressar os sentidos e os sentimentos do texto, de modo a deixá-los evidentes ao ouvinte, é recorrente também em $O$ idioma nacional na escola secundária, de Antenor Nascentes, e na antologia escolar Céu, terra e mar, de Alberto de Oliveira: o primeiro atribui à perfeição respiratória, responsável pelas inflexões adequadas da voz, a expressão autêntica da intenção das ideias do texto lido; e o segundo confere à entonação da voz a capacidade de transmitir a emoção do texto lido.

[...] Na respiração estará por assim dizer todo o trabalho expressivo. Se nos faltar o fôlego preciso, a voz não será perfeita, os sons sairão defeituosos, as inflexões viciadas, perturbando a própria intenção das ideias (SILVEIRA BUENO apud NASCENTES, 1935, p. 52-53).

III. - A entonação deve ser regulada pela emoção ou sentimento do texto (OLIVEIRA, 1914, p. 9-10).

A concepção de leitura em voz alta presente nos textos didáticos de Alberto de Oliveira, Silveira Bueno e Antenor Nascentes orienta-se para os gêneros literários clássicos e de maior prestígio, conforme o predomínio da cultura humanística tradicional e mantém também uma relação bastante estreita com o ideal de formação do orador. Esse ideal, que esteve presente na cultura antiga, apresenta-se também no ensino jesuítico praticado no Brasil do século XVI ao XVIII. A persistência dessa tradição no ensino continua ainda por muito tempo em nosso país, como é possível notar na importância dada à retórica no currículo do ensino secundário do século XIX, bem como no modo como a disciplina escolar de Português se apropriou de preceitos retóricos ao longo de sua história, da segunda metade do século XIX até o início do XX.

\section{O ensino da leitura em voz alta: aproximações com a arte retórica}

Depois do fim da Idade Média, quando a Retórica antiga é reativada no movimento contra-reformista da Igreja Católica, a partir do Concílio de Trento, no século XVI, a retórica - enquanto interpretação escolástica de conceitos e preceitos retóricos gregos e latinos - tornou-se uma das principais disciplinas do ensino jesuítico. No Brasil Colonial, essa retórica, além de ser institucionalizada nos colégios da Companhia de Jesus - que aqui se instalaram em 1549 e funcionaram até 1760, data em que a Companhia foi expul- 
sa pelo Marquês de Pombal -, esteve presente também nas práticas artísticas de poetas, oradores, historiadores e autores de prosa de ficção. A arte retórica praticada no ensino, na oratória e na escrita correspondia ao costume de recorrer a normas e preceitos da técnica de falar bem (tékhné rethoriké), descrita primeiramente por Aristóteles e retomada em tratados romanos (ars bene dicendi), como o do autor anônimo de Ad Herennium, os textos de Cícero, a Arte Poética, de Horácio, e a Instituição oratória, de Quintiliano, etc. (HANSEN, 2011, p. 25-26).

Nos colégios jesuítas, onde a elite colonial brasileira era educada com o fim de dirigir a sociedade, de modo a consolidar o projeto colonizador de Portugal e fortalecer os laços da Colônia com a Metrópole, ministrava-se o curso de Letras Humanas. De acordo com o Ratio studiorum de 1599, método pedagógico dos jesuítas, esse curso tinha duração média de seis ou sete anos e abrangia gradativamente cinco classes: gramática inferior, gramática média, gramática superior, humanidades e retórica (FRANCA S. J., 1952, p. 47-48). Essa forma de estudo gradual alicerçava-se em preceitos da cultura greco-romana, que estabeleciam a gramática como propedêutica à retórica, disciplina com a qual se concluíam os estudos nos colégios e, portanto, a formação do orador.

Até a segunda metade do século XIX, a retórica funciona ainda como principal modelo de representação e continua sendo transmitida no ensino, como é possível observar no currículo do Colégio Pedro II (HANSEN, 2011, p. 25-26). Fundado em 1837 e concebido como estabelecimento padrão para o ensino secundário brasileiro, o Colégio Pedro II teve implantada em 1839 a primeira cadeira de Retórica do Rio de Janeiro. A disciplina, juntamente com os conhecimentos ministrados em Poética, Literatura e Português, durante quase todo o período oitocentista, visava à formação de Bacharéis em Letras; originando escritores e oradores hábeis no manejo dos preceitos retórico-poéticos, os quais se dedicariam à escrita literária ou jornalística, à ocupação de cargos públicos ou seguiriam cursos superiores para o exercício das profissões liberais (Cf. SOUZA, 1999, p. 30, 8692). A importância dada à eloquência, por essa elite intelectual e econômica brasileira, se faz notar até o final do século XIX e ecoa ainda na primeira metade do século XX.

Ao analisar o currículo do Colégio Pedro II, Márcia Razzini (2000, p. 42) observa que a disciplina escolar Português, tendo sido institucionalizada em 1838 como estudos de gramática portuguesa, passa a incluir também em seu programa, a partir da década de 1850, práticas de leitura e recitação, as quais eram antes reservadas às cadeiras de Retórica e Poética. Assim, essas atividades são recomendadas (além de gramática e exercícios ortográficos) nos planos de ensino de Português dessa instituição, de 1858 a 1863, para o 
$1^{\circ}$ ano, série em que a disciplina era oferecida ${ }^{5}$. No currículo de 1870 - quando as aulas de Português, além de ocorrerem no $1^{\circ}$ ano, se estendem ao $2^{\circ}$ e $3^{\circ}$ ano -, são indicadas "a leitura em voz alta, clara e pausada, com as devidas inflexões, de modo que a pronúncia seja perfeita e guarde-se pontuação", bem como a recitação, que consistia em o aluno ter "decorado um trecho depois de bem explicado e compreendido por ocasião da leitura". Em 1877, para o $1^{\circ}$ e $2^{\circ}$ ano, sugerem-se a "leitura expressiva e recitação de cor de prosadores e poetas", duas horas por semana; sendo que no $2^{\circ}$ ano, "o professor designa[ria] os trechos em prosa ou verso que os alunos te[riam] de recitar na classe. [...] e os alunos, depois de tê-lo decorado, recitar[iam] no dia seguinte com a devida congruência, expressão e beleza". Conforme o programa de ensino de 1881, a "leitura e recitação de prosadores e poetas brasileiros e portugueses”, com explicação do trecho lido, continuariam a ser realizadas no $1^{\circ}, 2^{\circ}, 3^{\circ}, 4^{\circ}$ e $5^{\circ}$ ano do secundário. Em 1891, quando a instituição passa a denominar-se Ginásio Nacional, devido à instauração do regime republicano, são indicados para o $2^{\circ}, 3^{\circ}$ e $4^{\circ}$ ano:

\footnotetext{
$2^{\circ}$ ano

Português

[...]. Leitura e recitação de trechos de prosadores e poetas brasileiros e portugueses do século atual, explicação do sentido preciso de cada período e de cada parágrafo.

$3^{\circ}$ ano

Português

[...]. Leitura e recitação de trechos de prosadores e poetas brasileiros e portugueses, explicação do sentido geral de todo o trecho lido ou recitado. $4^{\circ}$ ano

Português

Leitura e recitação de trechos de prosadores e poetas brasileiros e portugueses, exposição do conteúdo de cada trecho por outras palavras (BRASIL, 1891 apud REVISTA PEDAGÓGICA, 1891, p. 64-75).
}

Os exames preparatórios de português, exigidos para o ingresso nos cursos superiores, também contemplavam a leitura expressiva. Assim, o Decreto n. 12 de 9 de dezembro de 1892, que tratou da "reorganização do ensino público no Estado das Alagoas" e a legislação do ensino da capital do Rio de Janeiro de 1895, ambos os documentos publicados na Revista Pedagógica (órgão da União), respectivamente em março de 1894 e dezembro de 1895, dividiam esses exames em duas partes, uma escrita e outra oral. Nesta última parte, a oral, eram requeridos "leitura expressiva de um trecho sorteado de prosador e

\footnotetext{
${ }^{5}$ Os programas de Português do Colégio Pedro II, aqui referidos, foram compilados por Razzini (2000, p.
} 283-338); exceto o de 1891, que foi publicado na Revista Pedagógica, em maio de 1891 (p. 64-75). 
poeta de nota, resumo de seu conteúdo a livro fechado, explicação de termos e análises” (ALAGOAS, 1892 apud REVISTA PEDAGÓGICA, 1894, p. 174; BRASIL, 1895 apud REVISTA PEDAGÓGICA, 1895, p. 388).

Em 1931, após ter vigorado treze programas diferentes desde 1892, no colégio Pedro II, e tendo sido criado o Ministério da Educação e Saúde Pública, durante o governo de Getúlio Vargas, fica estabelecido um novo programa de Português, elaborado no âmbito da Reforma Francisco Campos. De acordo com o documento, a "recitação de pequenas poesias, previamente interpretadas" deveria ocorrer na primeira e na segunda série do ciclo fundamental:

Primeira e segunda séries

Leitura de trechos de prosadores e poetas contemporâneos, escolhidos de acordo com a capacidade média da classe. Explicação dos textos. Estudo metódico do vocabulário. Reprodução oral do assunto lido.

Recitação de pequenas poesias, previamente interpretadas (BRASIL, 1931 apud RAZZINI, 2000, p. 344-346).

Quando Antenor Nascentes elabora $O$ idioma nacional na escola secundária, publicado em 1935, é com as normas deste programa de 1931 que seu livro procura estar em consonância. Assim, o manual parece ter o objetivo de funcionar como subsídio ao professor de português na execução do currículo, oferecendo-lhe métodos de ensino e explicações dos conteúdos exigidos para a 1 $1^{\mathrm{a}}, 2^{\mathrm{a}}$, 3a $3^{\mathrm{a}}$ a e $5^{\mathrm{a}}$ séries do curso fundamental do ensino secundário. Contudo, o texto de Nascentes apresenta recomendações que já faziam parte dos planos de ensino do Colégio Pedro II desde 1858, data em que a disciplina Português passou a incluir leitura e recitação em seu programa. Desse modo, tanto o livro de Antenor Nascentes quanto os programas de ensino de Português vigentes entre 1858 e 1931, no que concerne ao ensino da leitura, refletem o ideal de formação do orador, ou seja, o domínio de uma eloquência específica, de prestígio, exercitada com os gêneros poéticos, mas que fundamentaria uma redução às figuras de linguagem, que forneciam o repertório técnico para a produção de outros gêneros e para a formulação de outros textos. Esse ideal é inclusive exposto por Antenor Nascentes na obra didática analisada:

Devem fazer-se muitas leituras, a fim de que o aluno aprenda a ler sem erros nem vícios de pronúncia, a fim de que se acostume a ritmar bem as frases.

Cumpre também fazer exercícios de recitação e declamação.

Um homem culto e educado não tem acanhamento para falar, sabe manter- 
se de pé em atitude conveniente, não se embaraça com a colocação das mãos.

Além disto, os exercícios de declamação concorrem para a boa expressão (NASCENTES, 1935, p. 44).

Retomando a tradição da Retórica Clássica, que se destinava a formar o "cidadão", observamos uma dada permanência de uma longa tradição retórica no ensino da leitura em voz alta até os anos de 1970, no nível secundário, destinado a formar o "homem culto e educado", logo, um erudito mais do que um orador público, conforme indiciam outros manuais do professor, publicados posteriormente, como Português através de textos, de Magda Soares (9a ed. 1969), que desde sua publicação contou com sucessivas edições, assim como programas de ensino que vigoraram entre 1951 e 1961.

Embora a leitura em voz alta e a recitação não sejam mencionadas no programa de 1942, instituído na Reforma Capanema, a "leitura expressiva" volta a ser novamente recomendada em 1951, nas "Instruções metodológicas para execução do programa de Português", que acompanham o programa oficial da disciplina que substituiu o de 1942; e, posteriormente, na "Amplitude e desenvolvimento das matérias obrigatórias", emitidos junto à Lei de Diretrizes e Bases da Educação Nacional de 1961:

\footnotetext{
Leitura expressiva, vocabulário e ortografia

$[\ldots]$

Com esse caráter predominantemente educativo prosseguirá a leitura por todo o curso secundário; mas tão cedo quanto possível começará o professor a tirar dela tudo o que seja necessário para a cultura intelectual dos alunos, esforçando-se por estimular neles o gosto literário e exigindolhes, cada vez mais, expressão correta e elegante não só no falar, senão também no escrever (BRASIL, 1951 apud RAZZINI, 2000, p. 366).

$1^{\circ}$ - Expressão oral

[...]

As observações de caráter gramatical e estilístico serão precedidas da leitura expressiva do texto e da exposição oral, resumida, uma vez esclarecido aquele em todas as suas dificuldades. Quando a unidade do texto não for completa, caberá ao professor situá-lo na obra de que foi extraído, a fim de que o aluno possa bem compreendê-lo e apreciá-lo (BRASIL, 1961 apud RAZZINI, 2000, p. 370).
}

Na década de 1960, as críticas que já vinham sendo desferidas desde os anos de 1920 à prática da leitura oral no ensino, em artigos de revistas de ensino, pelos pedagogistas da Escola Nova, aparecem também em manuais para o ensino secundário, como 
Português através de textos, manual do professor elaborado por Magda Soares. De acordo com o livro escolar mencionado, a leitura em voz alta provocaria a distração pelo som da voz, atrapalhando, assim, a compreensão do texto lido (Cf. SOARES, 1969, p. 42). Por outro lado, embora a autora critique a leitura em voz alta, considera-a como vantajosa, principalmente por ser um "precioso auxiliar da expressão oral, na medida em que treina o aluno na articulação clara, boa dicção, educação da voz, segurança e naturalidade no falar":

[...] a leitura oral apresenta também vantagens que não devem ser desprezadas. Uma delas é seu valor socializante, cooperando na desinibição de alunos tímidos e retraídos (valor particularmente importante nas primeiras séries ginasiais). Por outro lado, a leitura oral é precioso auxiliar da expressão oral, na medida em que treina o aluno na articulação clara, boa dicção, educação da voz, segurança e naturalidade no falar. Além disso, é quando um aluno lê, e os outros apenas ouvem, com os livros fechados, que surge excelente oportunidade para desenvolver a capacidade de ouvir com atenção (SOARES, 1969, p. 42, grifo da autora).

Considerando a leitura em voz alta como uma prática vantajosa e que por isso deveria ser ensinada, Magda Soares passa então a apresentar uma "técnica da leitura oral", cuja finalidade parece ser a de auxiliar o professor a dirimir os erros no ensino deste tipo de leitura, realizando-o de forma mais acertada. O desenvolvimento dessa técnica implicaria seguir algumas recomendações, tais como: 1) a leitura oral deveria ser ouvida, sem ser acompanhada nos livros pelos ouvintes; 2) perguntas de compreensão deveriam ser feitas pelo professor antes e/ou após a leitura; 3) a leitura do texto deveria ser efetuada integralmente por um só leitor; 4) quando o texto fosse mais difícil, como no caso da poesia, a leitura deveria ser realizada pelo professor; 5) o aluno deveria preparar-se previamente para a leitura oralizada; 6) a leitura oral deveria ser seguida da leitura silenciosa.

Diferentemente do que ocorre nos livros O idioma nacional na escola secundária, de Antenor Nascentes, Manual de califasia e arte de dizer, de Silveira Bueno, e Céu, terra e mar, de Alberto de Oliveira, em Português através de textos, Magda Soares inverte a ordem entre leitura oral e silenciosa, de modo que aquela permita o melhor desempenho desta e não seu contrário. Afirma Soares:

Frequentemente é aconselhável também que se faça seguir à leitura oral uma leitura silenciosa dos alunos, a fim de que se complete a compreensão, pelo menos enquanto não estão eles suficientemente treinados no ouvir atenta e compreensivamente (SOARES, 1969, p. 44). 
Enquanto os demais autores centravam suas orientações na figura do leitor, sugerindo as atitudes adequadas, concernentes a este, para a boa leitura oral, esta última autora engloba também a figura do ouvinte. De acordo com o texto didático de Magda Soares, além das vantagens para quem lê, "a leitura apenas ouvida” levaria ao desenvolvimento da capacidade de ouvir com atenção (Cf. SOARES, 1969, p. 43-44).

Uma certa ambivalência em relação à leitura em voz alta na exposição de Magda Soares pode ser explicada, de um lado, pela incorporação nos enunciados da autora do ideário da Escola Nova e, de outro, pela preservação, em seu discurso, de uma prática que já integrava a história da cultura escolar. Tendo em vista que a cultura escolar é formada por um conjunto de práticas engendradas por coerções pedagógicas e didáticas que acompanham em permanência o ensino oferecido no interior da escola (Cf. CHERVEL, 1998, p. 7), ao reconhecer a leitura oralizada como vantajosa e ao fornecer uma técnica da leitura oral, Magda Soares, assim como Antenor Nascentes, Silveira Bueno e Alberto de Oliveira, dialoga com um elemento dessa cultura, promovendo a sua conservação.

\section{Considerações finais}

A importância conferida à leitura em voz alta no ensino secundário de então relaciona-se às finalidades dessa etapa da escolarização, que se diferenciavam daquelas do ensino primário. Conforme Souza (2008, p. 89), enquanto a escola pública primária tinha sido concebida como educação popular de caráter utilitário, na transição do século XIX para o XX, iniciando a sua expansão nas regiões urbanas ainda nesse período, a escola secundária, até pelo menos a década de 1940, continuava atendendo a um pequeno grupo social, composto pelos filhos de famílias da oligarquia agrária, de industriais, de grandes comerciantes, de profissionais liberais e da incipiente classe média citadina. Nesse sentido, visto que a escola primária urbana visava à formação da classe trabalhadora da cidade, a prática da leitura silenciosa na escola, segundo os pedagogistas da Escola Nova, habilitaria esses trabalhadores a uma apreensão mais veloz das informações escritas, cada vez mais crescentes na sociedade urbana brasileira do início do século XX (VIDAL, 2011, p. 505-509).

A leitura oralizada desempenhava à época uma dupla função pedagógica: permitia ensinar a decodificar, fomentando o reconhecimento das relações entre grafemas e formas, estabelecendo um ritmo adequado desse reconhecimento e da elocução; assim como permitia aos professores monitorar os desempenhos, homogeneizá-los, controlar a disciplina, evitar a dispersão, coletivizar as ações em sala. Por outro lado, uma vez que 
a escola secundária voltava-se a uma pequena elite econômica e intelectual, preparando seus filhos para o ingresso nas faculdades de Direito, Medicina e Engenharia, esta se preocupava em oferecer-lhes estudos desinteressados, para aquisição da cultura de prestígio, o que se pode aventar em função da importância até então dada ao "verso", que exigia desempenhos de leitura oralizada específicos. As recomendações de leitura em voz alta, relativas aos versos, indiciam não apenas a importância que se atribuía a esse tipo de texto.

A regularidade de sua presença nos materiais didáticos destinados ao ensino secundário e as recomendações especiais dedicadas ao modo como deveriam ser lidos os textos e os tipos de textos recomendados não indiciam necessariamente o predomínio, importância ou ampla circulação na sociedade de então dessa forma de ler e de ensinar a ler, mas antes parecem indiciar sua raridade e a manutenção de seus usos e circulação rarefeitos que, entre outros efeitos, produzia uma distinção social entre aqueles destinados a ocupar os postos subalternizados e aqueles que, provenientes da elite socioeconômica, comporiam as "elites condutoras do país".

\section{Referências}

ALAGOAS. Decreto n. 12 de 9 de dezembro de 1892. Reorganização do ensino público no Estado das Alagoas. In: Revista Pedagógica, Rio de Janeiro, Pedagogium, Secretaria de Estado dos Negócios da Instrução Pública, Correios e Telégrafos, p. 174, mar. 1894.

ARISTÓTELES. Poética. Tradução de Eudoro de Sousa. Lisboa: Imprensa Nacional Casa da Moeda; F.C.S.H. da Universidade Nova de Lisboa, 1986.

BASSETO, Bruno Fregni. Apresentação. In: QUINTILIANO, Marcos Fábio. Instituição oratória. Tradução e notas de Bruno Fregni Basseto. Campinas: Editora da Unicamp, 2015, tomo I.

BRASIL. Programa do ensino do Ginásio Nacional do ano de 1891. In: Revista Pedagógica, Rio de Janeiro, Pedagogium, Secretaria de Estado dos Negócios da Instrução Pública, Correios e Telégrafos, p. 59-96, mai. 1891.

BRASIL. Exames de preparatórios. In: Revista Pedagógica, Rio de Janeiro, Pedagogium, Secretaria de Estado dos Negócios da Instrução Pública, Correios e Telégrafos, p. 388, dez. 1895.

CHARTIER, Anne-Marie \& HÉBRARD, Jean. Discours sur la lecture (1880-1980). Paris: BPI - Centre Georges-Pompidou, 1989.

CHARTIER, Roger. A História Cultural: entre práticas e representações. Tradução de Maria Manuela Glhardo. Lisboa: Difel, 2002.

CHERVEL, André. La culture scolaire: une approche historique. Paris: Éditions Berlin, 1998. 
DE CERTEAU, Michel. (1990) Ler: uma operação de caça. In: A invenção do cotidiano: Artes de fazer. Trad. Ephraim Alves. Vol. 1.10 ed. Petrópolis: Vozes, 2004, p. 259-273.

DIONÍSIO TRÁCIO. Gramatica - comentarios antiguos. Tradução espanhola, introdução e notas de Vicente Bécares Botas. Madri: Editorial Gredos, 2002.

FRANCA S. J., Pe. Leonel. O método pedagógico dos jesuítas. O "Ratio Studiorum": introdução e tradução. Rio de Janeiro: Agir, 1952.

HALLEWEL, Laurence. O livro no Brasil: sua história. Tradução de Maria da Penha Villalobos, Lólio Lourenço de Oliveira e Geraldo Gerson de Souza. São Paulo: Editora da Universidade de São Paulo, 2005.

HANSEN, João Adolfo. A civilização pela palavra. In: LOPES, Eliane Marta Teixeira; FARIA FILHO, Luciano Mendes de; VEIGA, Cynthia Greive. 500 anos de educação no Brasil. Belo Horizonte: Autêntica, 2011.

LEGOUVÉ, Ernest. L'Art de la lecture à l'usage de l'enseignement secondaire. Paris: Imp. A. Lahure, 1877.

MANACORDA, Mario Alighiero. História da educação: da Antiguidade aos nossos dias. Tradução de Gaetano Lo Monaco. São Paulo: Cortez, 2010.

MANGUEL, Alberto. Uma história da leitura. Tradução de Pedro Maia Soares. São Paulo: Companhia das Letras, 1999.

MARROU, Henri-Irénée. História da educação na Antiguidade. Tradução de Mário Leônidas Casanova. São Paulo: Herder; Edusp, 1966.

NASCENTES,Antenor.Oidiomanacionalnaescolasecundária.SãoPaulo:Melhoramentos, 1935.

PARKES, Malcolm. Ler, escrever, interpretar o texto: práticas monásticas na Alta Idade Média. In: CAVALLO, Guglielmo e CHARTIER, Roger (orgs.). História da leitura no mundo ocidental 1. Tradução de Fulvia M. L. Moretto, Guacira Marcondes Machado e José Antônio de Macedo Soares. São Paulo: Editora Ática, 2002.

OLIVEIRA, Alberto de. Céu, terra e mar: prosa e verso. Rio de Janeiro; São Paulo; Belo Horizonte: Livraria Francisco Alves, 1914.

PFROMM NETTO, Samuel et al. O livro na educação. Rio de Janeiro: Primor/Instituto Nacional do Livro, 1974.

QUINTILIANO, Marcos Fábio. Instituição oratória. Tradução e notas de Bruno Fregni Basseto. Campinas: Editora da Unicamp, 2015, tomo I, livro I; tomo IV, livro XI.

RAZZINI, Márcia de Paula Gregório. O espelho da nação: a "Antologia nacional" e o ensino de português e de literatura (1838-1971). Tese de Doutorado. Instituto de Estudos da Linguagem, Universidade Estadual de Campinas, 2000.

ROBINS, Robert Henry. Pequena história da linguística. Tradução de Luiz Martins Monteiro. Rio de Janeiro: Ao Livro Técnico, 1983. 
SILVEIRA BUENO, Francisco da. Manual de califasia e arte de dizer: para uso das escolas normais e cursos de declamação. São Paulo: São Paulo Editora Ltda., 1930.

SOARES, Magda. Português através de textos. Manual do professor. Curso ginasial. 7 a edição. Belo Horizonte: Editora Bernardo Álvares S/A, 1969.

SOUZA, Roberto Acízelo de. O império da eloquência: retórica e poética no Brasil oitocentista. Rio de Janeiro: EdUERJ, EdUFF, 1999.

SOUZA, Rosa Fátima de. História da organização do trabalho escolar e do currículo no século XX: (ensino primário e secundário no Brasil). São Paulo: Cortez, 2008.

SVENBRO, Jesper. A Grécia arcaica e clássica: a invenção da leitura silenciosa. In: CAVALLO, Guglielmo; CHARTIER, Roger (orgs.). História da leitura no mundo ocidental I. Tradução de Fulvia M. L. Moretto, Guacira Marcondes Machado e José Antonio de Macedo Soares. São Paulo: Ática, 2002.

VIDAL, Diana Gonçalves. Escola Nova e processo educativo. In: LOPES, Eliane Marta Teixeia; FARIA FILHO, Luciano Mendes; VEIGA, Cynthia Greive (orgs.). 500 anos de educação no Brasil. Belo Horizonte: Autêntica, 2011.

ZUMTHOR, Paul. A letra e a voz: a "literatura medieval". Tradução de Amálio Pinheiro e Jerusa Pires Ferreira. São Paulo: Companhia das Letras, 1993.

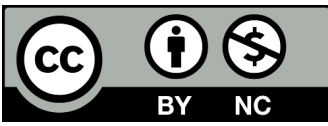

Data de submissão: 25/02/2020

Data de aceite: $28 / 05 / 2020$ 